\title{
The International Impact of COVID-19 and "Emergency Remote Teaching" on Computer Science Education Practitioners
}

\author{
Tom Crick*, Cathryn Knight*, Richard Watermeyer ${ }^{\dagger}$, Janet Goodall* \\ ${ }^{*}$ School of Education, Swansea University, Swansea, UK \\ Email: \{thomas.crick,cathryn.knight,j.s.goodall\}@ swansea.ac.uk \\ ${ }^{\dagger}$ School of Education, University of Bristol, Bristol, UK \\ Email: richard.watermeyer@bristol.ac.uk
}

\begin{abstract}
In March 2020, the COVID-19 global pandemic imposed "emergency remote teaching" across education globally, leading to a rapid shift to online learning, teaching and assessment (LT\&A) across all settings, from schools through to universities. This paper looks specifically at the impact of these disruptive - and ongoing - changes to those teaching the discipline of computer science (CS) across the world. Drawing on the quantitative and qualitative findings from a large-scale international survey $(N=2,483)$ conducted in the immediate aftermath of the shift online between March-April 2020, we report how those teaching CS across all educational settings and contexts $(n=327)$ show significantly more positive attitudes towards the move to online LT\&A than those working in other disciplines. When comparing educational setting, CS practitioners in schools felt more prepared and confident than those in higher education; however, they expressed greater concern around equity and whether students would be able to access and meaningfully engage with online LT\&A. Furthermore, while CS practitioners across all sectors consistently noted the potential opportunities of these changes, they also raised a number of wider concerns on the impact of this shift to online, especially on workload and job precarity. Concerns were also raised by international $C S$ practitioners regarding the ability to effectively deliver technical topics online, as well as the impact on formal examinations and assessment. This rapid response snapshot of the early impact of COVID-19 on CS education internationally provides insight into emerging LT\&A strategies that will likely continue to be constrained by coronavirus into 2021 and beyond.

Index Terms-COVID-19, emergency remote teaching, practitioner perceptions, schools, universities, computer science education
\end{abstract}

\section{INTRODUCTION}

The impact of the COVID-19 global pandemic is still incalculable; it has affected, and continues to affect, significant health and wellbeing impacts, profound social suffering, significant cultural disruption, and deep economic hardship. While indiscriminate in terms of whom it infects, it has largely punished society's most vulnerable and less fortunate [1]-[3]; worse now, it appears that the virus may have to be tolerated on an long-term basis [4].

The impact of the pandemic on education systems across the world has been profound [5], [6], presenting significant challenges for learning, teaching and assessment (LT\&A) [7][9]. There have been significant responses from governments, organisations and institutions at all levels and settings internationally [10]; from major national and international policy initiatives to support learners and maintain quality and standards, to longer-term government inquiries on the impact of COVID-19 on education and children's services.

While there has been a rapid shift to "emergency remote teaching" during the pandemic, the general impact and efficacy of digital learning and educational technologies is still unclear in the formal academic literature, being dependent on specific educational settings and LT\&A context. Whilst a range of national and international research studies have shown benefits of the successful application of digital LT\&A across a variety of contexts and settings, the widespread adoption, implementation and evaluation of educational technologies has yet to be fully realised [11]-[14]. The research and policy debate regarding the efficacy, utility and impact of educational technology and digital practice is ongoing, as exemplified by major digital LT\&A strategies and initiatives in schools, for example across the UK [15]-[18] and the USA [19], as well as recent work on digital practice in higher education (HE) [20][22]. We have also seen recent evidence assessments of remote learning [23], alongside guidance on how digital technologies can support learning [24]; this is contextualised by how faceto-face learning is often perceived to be "better quality" than online approaches [25], [26].

It is clear that the academic discipline of computer science (CS) - and indeed the wider technology sector - has much to offer to address the breadth of societal challenges resulting from the COVID-19 pandemic [27]; from computational modelling, data science, the wide application of AI and machine learning, as well as understanding the wider legal, social, ethical and professional issues from contact tracing, personal data sharing/storage, and impingement of civil liberties [28]-[33]. There has also been recent analysis on the impact of COVID-19 on various international CS research communities [34], [35] - as we have seen across international scientific research communities more broadly [36], especially on ongoing projects, careers, and dissemination of work [37]. We build on recent work [38], that has also looked at the impact on the UK's CS education community [39]; however, 
there has been little focus on what this means for international CS education and practitioners, especially thinking about the range of specific disciplinary challenges for LT\&A, across all settings and levels. This wider work also directly links to recent major international changes to CS curricula, qualifications and practice (e.g. in the UK [40], [41]), as well as the emerging focus on the required skills and infrastructure interventions to support the global post-COVID economic recovery [42]-[44].

\section{RESEARCH QUESTIONS}

To address this knowledge gap on the impact of COVID19 on the international CS research community, we undertook an anonymous survey of international CS educators on their perspectives as practitioners on the rapid shift to "emergency remote teaching" and transitioning online at the height of the COVID-19 crisis, and what they identify and forecast as its immediate and prospective impacts. The data was collected in the immediate aftermath of the forced institutional lockdowns and shift to online LT\&A between March-April 2020. It aimed to provide insight into the impact on practitioners and institutions (and thus, indirectly, students); emerging institutional and national-level policy and practice; what might this mean for the next and following academic years; and whether this might change approaches to LT\&A for the discipline as a result. The analysis and discussion that follows is based upon the perspectives of $n=327$ practitioners drawn from across all educational settings, institutions, and the career hierarchy, and what they recognise to be the major consequences of COVID19 , the rapid transition to online LT\&A, and the challenges of maintaining "continuity of learning". The study thus aimed to answer the following questions:

- How did the perceptions of the rapid move to online LT\&A differ between CS practitioners and other disciplines?

- How did the perceptions of the rapid move to online LT\&A differ by CS practitioner setting?

- What are the key opportunities and challenges resulting from the COVID-19 global pandemic as perceived by CS practitioners?

By capturing the hopes and fears of the international CS education community in the face of seismic and, as may prove to be, permanent shifts, we wish to be able to better understand and adapt to a shifting LT\&A landscape, as well as how best to support students.

$N . B$. With regards to the consistent naming of the discipline throughout this paper and acknowledging differences in various nations and jurisdictions, we use "computer science" (CS) to refer to the cognate disciplines as covered by the various ACM Curricula Recommendations [45].

\section{METHODS}

\section{A. Sample}

The survey aimed to investigate how international CS education practitioners have viewed the move to online LT\&A. The sample was taken from a larger survey in which the target population was those who are actively involved in the delivery of LT\&A across the education sector. Those who did not meet this criterion were excluded from analysis post-hoc.

We adopted a convenience sampling approach in distributing the online Qualtrics survey, whereby a link to the survey was shared via mailing lists, through professional networks and related education organisations (for example, through the ACM SIGCSE members lists), as well as via social meda (e.g. Twitter and LinkedIn). While the use of convenience sampling does not allow generalisation to a representative population, this sampling technique allowed us to document patterns within the observed population, with minimal time and cost restrictions.

After excluding those that did not meet the participant requirement, 2,483 international educational practitioners responded to the survey. This included 1,465 respondents from the HE (university) sector (59\%) and 1019 respondents from schools (41\%). 327 participants indicated that they taught CS. This included 196 from the HE sector (59.9\%), 131 from schools $(40.1 \%)$.

The survey was launched on 26 March 2020 following the announcement of closures across various educational settings in the UK, Europe and USA, and closed four weeks later. Due to the chosen distribution method we cannot calculate the response rate; however, of those who started the survey, $84.9 \%$ completed it.

\section{B. Questionnaire}

On the first page of the questionnaire, respondents were informed that the research study was designed to ascertain their views, perceptions and experiences of the move to online LT\&A as CS practitioners, in response to COVID-19. The first section of the questionnaire consisted of demographic questions in order to determine how participant characteristics impacted key variables. In order to identify those who teach $\mathrm{CS}$, respondents from the HE sector were asked to select their discipline from the UK Joint Academic Coding of Subjects (JACS) codes ${ }^{1}$. Those who worked in schools (K-12) were asked if they taught a particular subject; those that responded affirmatively were then asked to select their subject from a wider list containing subjects/disciplines commonly taught in schools.

Demographic questions were followed by five-point Likert scale questions (using strongly agree; agree; neither agree nor disagree; disagree; strongly disagree) exploring respondents' views of the changes, about how prepared and confident they felt about the move to online teaching. In addition, respondents were asked three open-ended questions in order to gain their overall insight into the impact of the changes:"Please provide any comments of how the online learning and teaching changes brought in as a response to COVID-19 will impact upon" followed by "your role", "your institution" and "your sector of education". Ethical approval for this study was obtained from the authors' institutional research ethics committees. The survey was piloted on a subsample of the

\footnotetext{
${ }^{1}$ https://www.hesa.ac.uk/support/documentation/jacs
} 
population before distribution to the wider international CS community.

\section{Analysis}

Quantitative bivariate chi-square $\left(\chi^{2}\right)$ analysis of the key variables was conducted in order to determine overall attitudes to online LT\&A and whether there were significant differences between those in CS and those in other disciplines. Furthermore, comparisons were made between those in schools and $\mathrm{HE}$ in order to determine whether there were significant differences between those working in different educational settings. Chi-square tests were utilised due to the categorical nature of the variables and to assess whether the observed cell counts are significantly different from the expected cell counts. For the purpose of the chi-square tests, the Likert scales were coded into a binary 'agree' and 'disagree' variables. This allowed for ease of interpretation and to see which groups were significantly more likely than expected to agree or disagree with each statement.

Qualitative analysis of the open-ended questions used thematic analysis, described as "a method for identifying, analysing and reporting patterns (themes) within data" [46]. This was done by firstly reading through the qualitative responses and numerically coding the data to identify whether comments were positive, negative or neutral. The responses were coded by two researchers to ensure inter-rater reliability (IRR=0.82). Within these codes potential themes were identified: "a theme captures something important about the data in relation to the research question and represents some level of patterned response or meaning within the data set" [46]. These themes were reviewed rigorously against the data to ensure that they were compatible with the data and accurately represented the comments.

\section{RESUlts}

\section{A. Quantitative Data}

Table I shows that those who work in CS are significantly more likely to say that they felt prepared $\left(\chi^{2}(1)=31.47\right.$, $\mathrm{p}<0.001)$, confident $\left(\chi^{2}(1)=31.44, \mathrm{p}<0.001\right)$, supported by their institution $\left(\chi^{2}(1)=9.91, \mathrm{p}=0.002\right)$, held a good working knowledge of appropriate technologies $\left(\chi^{2}(1)=63.66\right.$, $\mathrm{p}<0.001)$, had access to appropriate technologies $\left(\chi^{2}(1)=\right.$ 23.24, $\mathrm{p}<0.001)$ and were confident that their students could access online LT\&A $\left(\chi^{2}(1)=22.51, p<0.001\right)$. The figures presented in bold in both Table I and Table II had a $\mathrm{z}$ score of +1.96 , meaning that this category were significantly more likely than expected to agree with the statement; the figures in italics has a $\mathrm{z}$ score of -1.96 meaning that this category was significantly less likely than expected to agree with the statement.

The information presented in Table II demonstrates that within those that responded that they worked within CS there was also significant differences between education sectors. Those who work in schools $(84.3 \%)$ were significantly more likely to say they were prepared than those in HE $(69 \%)$ $\left(\chi^{2}(1)=8.39, \mathrm{p}=0.004\right)$. Practitioners from schools $(91.5 \%)$ stated that they were significantly more confident than those working in $\mathrm{HE}(78.7 \%)\left(\chi^{2}(1)=7.62, \mathrm{p}=0.006\right)$. Finally, those from schools $(39 \%)$ were significantly less confident that their students would be able access online LT\&A than those from $\operatorname{HE}(57.6 \%)\left(\chi^{2}(1)=8,2, \mathrm{p}=0.004\right)$.

\section{B. Qualitative Data}

1) School Practitioners: Positive Aspects:

"ICT has gone up massively as a valued skill - hopefully a trend that will be reflected and its impact will be increased in terms of curriculum timetabling." [school, Wales]

"We are in a pretty unique place because of what we teach. " [school, New Zealand]

Mirroring the quantitative results, the open-ended responses from school CS practitioners highlighted the potential benefits that the move to online LT\&A will have on education. As reflected in the quote above, respondents acknowledged the positive shift in emphasis on CS as a subject: "It may put further emphasis on computing as a subject, with so much technology in use" [school, England].

Respondents also acknowledged the direct impact on their own role as a subject specialist in CS: "As ICT coordinator my role is probably more important now than when in school" [school, Ireland]; "As the resident IT expert, I'm everyone's new best friend!" [school, England]. Thus, reinforcing the practitioner's own status as a perceived expert in educational technologies.

Furthermore, respondents spoke positively not only about the impact on CS as an academic discipline, but also about improvements in cross-curricular digital skills. School practitioners acknowledged the benefits of all staff upskilling in the area of digital technologies: "Greater staff awareness of education technologies" [school, New Zealand]; "As Digital lead for the school it should make embedding some skills a lot easier as staff have now had a crash course" [school, Wales]. More broadly, those in schools also mentioned the collegiate benefits of the whole school response to the change "This is bringing our staff together in some ways because we are all collaborating and sharing ideas" [school, USA].

2) School Practitioners: Negative Aspects:

"As a Computing teacher, most of my resources are already online. However, teaching programming techniques and complex concepts of computer science online is difficult." [school, UK]

However, while a number of positive messages came through, school CS practitioners also raised a number of concerns about the impact of online LT\&A. Reflecting the quantitative results, those in schools expressed concerns about students' ability to access LT\&A that would be made available online "I will need to be more proactive in trying to reach students who may be struggling to cope. Some are homeless, some don't have laptops, some have less than ideal home situations" [school, Ireland]. This particular concern was raised in response to the resource needed to study CS "[...] ensuring 


\begin{tabular}{|c|c|c|c|c|}
\hline \multirow[b]{2}{*}{ Survey statement } & \multicolumn{2}{|c|}{ Computer science } & \multicolumn{2}{|c|}{ Other disciplines } \\
\hline & $n^{*}$ & $\% *$ & $n^{*}$ & $\% *$ \\
\hline "I feel confident in my ability to facilitate online learning, teaching and assessment" & 215 & 84.0 & 1071 & 66.5 \\
\hline "My institution has been supportive in facilitating the move to online learning, teaching and assessment" & 220 & 86.6 & 1232 & 22 \\
\hline "I have a good working knowledge of the technologies that are available to support learning, teaching and assessment online" & 246 & 90.8 & 1061 & 66.8 \\
\hline "I can access appropriate technologies to support my online learning, teaching and assessment" & 265 & 95.0 & 1422 & 84.0 \\
\hline "I am confident that all of my students will be able to access the teaching and assessment that I make available online" & 122 & $\mathbf{5 0 . 0}$ & 538 & 34.3 \\
\hline
\end{tabular}

RESPONSES TO STATEMENTS BY DISCIPLINE (*NUMBER AND PERCENT OF THOSE AGREEING WITH STATEMENT COMPARED TO DISAGREEING)

\begin{tabular}{|c|c|c|c|c|}
\hline \multirow[b]{2}{*}{ Survey statement } & \multicolumn{2}{|c|}{ School } & \multicolumn{2}{|c|}{$\mathrm{HE}$} \\
\hline & $\mathrm{n}^{*}$ & $\% *$ & $\mathrm{n}^{*}$ & $\% *$ \\
\hline "I feel prepared to deliver online learning, teaching and assessment" & 97 & 84.3 & 107 & 69.0 \\
\hline "I feel confident in my ability to facilitate online learning, teaching and assessment" & 97 & 91.5 & 118 & 78.7 \\
\hline "My institution has been supportive in facilitating the move to online learning, teaching and assessment" & 89 & 85.6 & 131 & 87.3 \\
\hline "I have a good working knowledge of the technologies that are available to support learning, teaching and assessment online" & 113 & 94.2 & 133 & 88.1 \\
\hline "I can access appropriate technologies to support my online learning, teaching and assessment" & 111 & 94.1 & 154 & 95.7 \\
\hline "I am confident that all of my students will be able to access the teaching and assessment that I make available online" & 39 & 39.0 & 83 & 57.6 \\
\hline
\end{tabular}

RESPONSES TO STATEMENTS BY SECTOR (*NUMBER OF PERCENT OF THOSE AGREEING WITH STATEMENT COMPARED TO DISAGREEING)

computing students have access to the internet and computers [...] and have all the essential software downloaded" [school, Wales].

Furthermore, there was discussion about appropriate pedagogies for teaching CS "For this year, since most of what needed to be covered has been covered for my AP classes, and since the AP Exams have been watered down a bit for this year, things are okay. But if I were to have to go completely to online teaching, I might as well retire. There's something lost if I can't interact with my students in a classroom setting. Assessment takes a real dive." [school, USA], this lack of faceto-face interaction was a key concern for school practitioners "now that there is no face-to-face contact with students, the computer time is very demoralizing" [school, USA].

More general concerns were also raised about the impact on CS staff workload "I will be expected to provide additional content to support home learning" [school, New Zealand]. Within this theme, while some practitioners acknowledged the benefits to the status of their role as perceived experts in education technology, others raised concerns about the impact of this on their workload "So as well as being a teacher, I have set up the entire school platform, written how to guides for teachers, made tutorial videos and am doing online training to all other staff. It's supposed to be my holiday and I have worked all day every day" [school, England].

3) HE Practitioners: Positive Aspects:

"Overall, this may help us identify techniques that are particularly helpful in computer science education." [HE, USA]

"I think that everybody will begin seeing value in technology's place in education." [HE, UK]

As mirrored within the quantitative data, there were more positive themes emerging from the school CS practitioners. However, HE CS practitioners also recognised the positive impact of the changes on the CS discipline. As demonstrated in the above quotes, some acknowledged the system learning that may now take place as a result of the rapid changes; one practitioner stated that "computer science will boom" [HE, Canada].

Furthermore, the potential impact on the wider CS education sector was also acknowledged "I expect to see an increase in the number of students in CS education, as CS jobs can typically be performed remotely (e.g. from home) and are therefore more resilient in the face of stay at home orders" [HE, UK]. Like with school practitioners, there was also acknowledgement that those within CS are perhaps the best equipped to deal with these changes "Computer science will be one of the least hit as our colleagues and students are among the most capable when it comes to operating online" [HE, UK].

"COVID-19 has been a lightning rod that has catalysed a lot of much needed changes in my institution." [HE, UK]

HE CS respondents also mentioned the potential benefits to the HE sector as a whole: "HE will never be the same. However, this might provide an opportunity to rethink the role of $\mathrm{HE}$ - to educate rather than to train?" [HE, USA]. One practitioner acknowledged the benefits on the changes to the structural relationships within their department: "This disruption has had at least two strong internal advantages: Everybody has finally made an effort to transition to online learning; Older faculty have had to rely on the expertise of younger faculty (whom they were quick to dismiss until now)" [HE, USA].

Furthermore, there was acknowledgement that the work put in now may not be wasted in the longer term "Everyone is likely to leverage the current move online as much as they can. Nobody is going to waste the work that they are suddenly having to do now" [HE, Canada]. However, as discussed below, there were concerns about the longer-term move to online on the sector.

4) HE Practitioners: Negative Aspects: 
"My role is shifting towards advising and away from teaching; a major challenge will be students' mental health, not their ability to write Java code." [HE, USA]

"I am concerned that my institution thinks a move online is a move to more innovative and modern teaching, just by virtue of it being online." [HE, England]

The key theme emerging from the CS HE practitioner responses was the fragility of the sector as a whole. Comments such as "why would a student choose one school over another when everything is online?" [HE, Norway]; "I am concerned about how this will impact recruitment and enrolment next fall" [HE, USA] and "fear that some Universities may close" [HE, England] summarise practitioners concerns about the fragility of the $\mathrm{HE}$ sector as a whole within this climate. Respondents also raised concerns about the retention of staff "Major financial impact is likely to lead to major staff shortages, particularly in my discipline, where graduates can all command high salaries in industry" [HE, USA], along with wider concerns about the potential impact on the industry: "Produce less qualified graduates due to relaxed standards" [HE, USA].

Furthermore, respondents foresaw a longer-term move to online LT\&A "I think there will be greater pressure to do more online teaching. There will be an attitude that we were successful making this move in extraordinary circumstances. Surely, we can do the move permanently" [HE, Philippines] and "I expect we will be asked to do more online teaching in the future, having now proven it can work" [HE, Nigeria].

For CS, there was concern about the access to specialist software needed for their courses: "Access to specialist laboratories and equipment has been curtailed. Depending upon a student's specialism with Computer Science their experience could be more significantly affected. For example, those studying networking or robotics" [HE, South Africa]. In particular, concerns were raised about the more practical aspects of a CS degree course: "Specifically I work in an area that involves some hands-on practical projects. These cannot be replicated online, so the student experience will be significantly changed" [HE, Scotland]. Furthermore, concerns were raised about how effectively certain aspects of CS assessment can be done online "the difficulty in assessing student's knowledge as code is easy enough to test when doing coursework" [HE, Wales].

"Increased workload (already VERY overworked) [...] it is easier for students to contact me (good) but means the volume of queries and contacts increases which saps time (bad). Need to do increased admin [...] All in all bad for my career as I can't do any science." [HE, England]

As with school CS practitioners, concern was raised over the impact on workload. For those in HE there was particular concern about the impact on other aspects of their academic roles and responsibilities. In particular, respondents stated that "research will be the hard part" [HE, England]; "this has massively blown out the proportion of time I expected to spend teaching, and as such I am not engaging in the research I need to be doing" [HE, USA].

\section{Discussion}

"This is the beginning of a new era. Things will never be the same again." [HE, USA]

\section{A. Pedagogy and Practice}

The quantitative data showed that those from CS were significantly more positive about the move to online LT\&A in the immediate aftermath of educational closures, then those from other disciplinary areas. These results are, perhaps, unsurprising, given the likely proficiency of CS practitioners to use technology. They highlight that this perceived confidence with technology translates to its use for online LT\&A. When this was broken down further, while those from schools felt more prepared and confident in their ability to deliver online LT\&A, they were less confident about their students' ability to access the material.

"This is bringing our staff together in some ways because we are all collaborating and sharing ideas. My principal has been great about communicating with us on a daily basis." [school, England]

Central to both the positive and negative commentary was high-quality learning and teaching for CS, and especially appropriate pedagogic approaches. While some recognised the potential that moving teaching online could allow practitioners to be 'flexible' and 'creative' with their pedagogy, fostering increased collaboration between teams, practitioners expressed concern about how key foundation topics and threshold concepts in CS can be taught effectively without face-to-face instruction. Therefore, while some literature has demonstrated the use of technology to enhance teaching, a number of practitioners were concerned about its value and contribution to CS education, especially for key topics in CS, such as introductory programming and mathematical foundations, as well as more practical or collaborative topics such as robotics and group software development projects.

\section{B. Bridging the Skills Gap}

"As a Computing teacher, most of my resources are already online. However, teaching programming techniques and complex concepts of computer science online is difficult." [school, Wales]

"HE will move increasingly to online provision, sadly. Our technologies do not currently allow the creation and manipulation of shared mental representations which is necessary for effective teaching and learning of mathematics and computer science." [HE, England]

Yet, it could also be argued that the efficiency of online LT\&A may be overplayed by institutions and CS practitioners across all settings, who may be rapidly moving to teaching online without the necessary robust and sustainable investments in digital infrastructure, professional development 
and understanding of effective learning design and online pedagogy. As noted in the responses, there may be longer-term positive impact of this technological upskilling of educational practitioners, however, significant concerns were raised about the impact on workload due to these changes. There were also concerns raised about top-down, "one size fits all" institutional approaches, rather than evaluating and addressing disciplinaryspecific challenges and supporting appropriate pedagogic approaches.

\section{Infrastructure}

"Delay in critical upgrades to servers and increase in infrastructure. Need to expend further funds to have suitable hardware to loan to staff in these circumstances." [school, England]

Another theme that was acknowledged as a significant challenge was the demand on educational digital infrastructure. While CS practitioners acknowledged the potential opportunities of institutional financial investment in digital infrastructure, concern was raised about equity of access to these recourses. While it was acknowledged by some HE practitioners that CS students may be the least affected by this, there was broader concern for those that may not be able to access appropriate technologies (especially if there was a requirement for specialist equipment or software), and that it was easy to make assumptions about how and when students are able to engage with online learning. This concern was more consistently expressed by school practitioners.

"The difficulty is how to provide alternatives to specialised laboratory provision. We also have large numbers of international students, some of whom have now gone back to their home countries. Some of these have very poor or no access to technology and keeping in touch with them is challenging. Luckily our sector of education, computer science, means that both staff and students tend to have good knowledge of digital technologies and how they can support online learning but care still needs to be taken as not all students have good access from home or can adapt easily to an online version of education." [HE, UK]

\section{Limitations}

It is also necessary to identify the limitations of this research and to highlight the potential for how it can support future research in this area. As this research was conducted in the immediate aftermath of the move to online LT\&A, it could be argued that due to the rapid changes to the global crisis since March-April 2020, attitudes will have evolved since this data was collected (especially as we have moved into the 2020/2021 academic year). Furthermore, this study has grouped together international CS practitioners from across various educational settings. It could also be argued that the difference in experience of these practitioners is vast and, consequently, it is difficult to recognise them as a homogenous group. However, the coherence from the quantitative and qualitative results offers some strength to the insights into international CS education practitioners' perceptions during these radical changes. While this makes it potentially challenging to replicate, the results highlight the longer-term opportunities and challenges that the move to online LT\&A may bring about. Furthermore, it is clear that follow-up research needs to be conducted in order to better understand how perceptions have changed since this data was first collected in 2020 .

\section{CONCLUSIONS AND LOOKING FORWARD}

Many of the challenges and opportunities presented by COVID-19 and the rapid shift to "emergency remote teaching" in March 2020 as identified in this survey could be applied more broadly across the various international educational settings; especially the wider impact on practitioners [47][49]. In particular, there are significant concerns regarding impact on job precarity and security, career progression, financial sustainability of higher education institutions [38], robustness and integrity of national-level qualifications and examinations [50], issues of equity and access to technology, as well as the health and wellbeing of practitioners (and students) due to increased workloads and expectations. It is also important to acknowledge the ongoing media narrative regarding online teaching being perceived as lower quality than face-to-face teaching [25], [26]; however, teaching quality is more important than how lessons are delivered [23], while technology can be used to improve the quality of explanations and modelling, and can play a role in improving feedback and assessment [24], as well as new approaches to accreditation [51], [52] and micro-credentialing [53].

The rapid adoption of digital technologies for almost all LT\&A activities that could previously have taken place within the physical space of an educational institution presents opportunities to rethink how many academic practices might take place in virtual environments [54]. These resultant shifts in digital culture, identity, and new demands on educational leadership and management - especially in schools [18], [55] - and perhaps specific challenges for CS as a discipline [35], [39]. However, reshaping the post-pandemic digital structure of education also risks exacerbating existing inequalities in the use of digital technologies (especially in the context of digital exclusion and digital/data poverty [56], [57]), as well as opening up new areas of academic life to surveillance and control [58], directly linking to wider priorities surrounding the importance of legal, social, ethical and professional issues in $\mathrm{CS}$ education.

However, there are a number of specific issues for CS practitioners internationally that provides valuable insight and context for the discipline as we move with some uncertainty into 2021 and beyond. In particular, the increased prominence of technology in an educational context provides opportunities for showcasing the importance of cross-curricular digital and data skills [18], as well as the explicit value of CS in an interdisciplinary STEM context [59]. This clearly resonates with recent international CS curricula and qualifications reforms, especially as CS is starting to become increasingly 
established as a school-level subject [41], [60]-[62]. There is also an increasing focus on identifying and refining effective pedagogic approaches for LT\&A on key foundation topics in CS - and especially for CS1 - such as mathematical foundations, introductory programming and cybersecurity [63]-[68]. However, there are concerns of top-down, "one-size-fits-all" institutional or national approaches that do not recognise the unique characteristics of LT\&A in CS across the various settings and levels. Further work is required to better identify, evaluate and share best practice for some of these areas, especially with regards to assessment, certification, accreditation and qualifications [69]-[72], as well as professional development and support for CS practitioners, especially earlycareer academics [73], [74].

Finally, it is clear there will be a huge demand for digital skills and infrastructure [42], [75]-[77] to support global postCOVID economic renewal [78]. Based on the data obtained from this rapid response survey of international CS practitioners, we anticipate continued evaluation, development and refinement of best practice for online LT\&A for CS as we move into the 2020-2021 academic year and beyond. Whilst it may be possible to frame COVID-19 as a catalyst for educational change [79], it is imperative that follow-up studies are conducted to capture this ongoing impact on computer science education, especially if we need to prepare for future pandemics [80].

\section{REFERENCES}

[1] J. von Braun, S. Zamagni, and M. S. Sorondo, "The moment to see the poor," Science, vol. 368, no. 6488, 2020.

[2] The Lancet, "Editorial: Redefining vulnerability in the era of COVID19," The Lancet, vol. 395, 2020.

[3] W. Van Lancker and Z. Parolin, "COVID-19, school closures, and child poverty: a social crisis in the making," The Lancet Public Health, vol. 5, no. 5, pp. E243-E244, 2020.

[4] S. M. Kissler, C. Tedijanto, E. Goldstein, Y. H. Grad, and M. Lipsitch, "Projecting the transmission dynamics of SARS-CoV-2 through the postpandemic period," Science, vol. 368, no. 6493, pp. 860-868, 2020.

[5] UNESCO, "COVID-19 Impact on Education," https://en.unesco.org/ covid19/educationresponse, July 2020.

[6] R. Armitage and L. B. Nellums, "Considering inequalities in the school closure response to COVID-19," The Lancet Global Health, vol. 8, no. 5, p. E644, 2020.

[7] A. Doucet, D. Netolicky, K. Timmers, and F. Tuscano, "Thinking about Pedagogy in an Unfolding Pandemic: An Independent Report on Approaches to Distance Learning During COVID-19 School Closures," March 2020.

[8] F. M. Reimers and A. Schleicher, "A framework to guide an education response to the COVID-19 Pandemic of 2020," March 2020, OECD.

[9] R. E. Ferdig, E. Baumgartner, R. Hartshorne, R. Kaplan-Rakowski, and C. Mouza, "Teaching, Technology, and Teacher Education during the COVID-19 Pandemic: Stories from the Field," June 2020, Association for the Advancement of Computing in Education (AACE).

[10] World Health Organisation, "WHO Coronavirus Disease (COVID-19) Dashboard," https://covid19. who.int, 2020.

[11] R. Luckin, B. Bligh, A. Manches, S. Ainsworth, C. Crook, and R. Noss, "Decoding Learning: The Proof, Promise and Potential of Digital Education," https://www.nesta.org.uk/report/decoding-learning/, 2012.

[12] B. Means, Learning Online: What Research Tells Us About Whether, When and How. Routledge, 2014, iSBN: 978-0415630290.

[13] J. Conrads, M. Rasmussen, N. Winters, A. Geniet, and L. Langer, "Digital Education Policies in Europe and Beyond: Key Design Principles for More Effective Policies," 2017, European Commission, Joint Research Centre, JRC109311.
[14] R. E. Mayer, "Thirty years of research on online learning," Applied Cognitive Psychology, vol. 33, no. 2, pp. 152-159, 2018.

[15] Scottish Government, "Enhancing learning and teaching through the use of digital technology: A digital learning and teaching strategy for Scotland," https://www.gov.scot/publications/enhancing-learning-teachingthrough-use-digital-technology/, September 2020.

[16] Welsh Government, "Digital Competence Framework guidance," https://hwb.gov.wales/curriculum-for-wales/cross-curricular-skillsframeworks/, June 2018.

[17] Department for Education, "Realising the potential of technology in education: A strategy for education providers and the technology industry," April 2019, UK Government.

[18] T. Crick, "COVID-19 as a Catalyst for Rethinking Digital Education: A View from Wales," Research Intelligence, no. 145, pp. 14-15, 2020.

[19] US Department of Education, "Use of Technology in Teaching and Learning," https://www.ed.gov/oii-news/use-technology-teachingand-learning, 2020.

[20] Jisc, "Learning and teaching reimagined: Change and challenge for students, staff and leaders," https://www.jisc.ac.uk/reports/learning-andteaching-reimagined-change-and-challenge, July 2020.

[21] World Economic Forum, "COVID-19: Why higher education in the US must embrace digital," https://www.weforum.org/agenda/2020/07/ covid19-higher-education-universities-digitalization/, July 2020.

[22] QAA, "Building a Taxonomy for Digital Learning," https://www.qaa.ac.uk/docs/qaa/guidance/building-a-taxonomy-fordigital-learning.pdf, June 2020

[23] EEF, "Remote Learning: Rapid Evidence Assessment," https://educationendowmentfoundation.org.uk/covid-19-resources/ best-evidence-on-supporting-students-to-learn-remotely/, April 2020.

[24] — - "Using Digital Technology to Improve Learning," https://educationendowmentfoundation.org.uk/tools/guidance-reports/ using-digital-technology-to-improve-learning/, December 2019.

[25] M. Paechter and B. Maier, "Online or face-to-face? Students' experiences and preferences in e-learning," The Internet and Higher Education, vol. 13, no. 4, pp. 292-297, 2010.

[26] BBC News, "Students 'must be warned if courses taught online'," https: //www.bbc.co.uk/news/education-52709516, May 2020.

[27] M. Calder, Q. Cutts, and J. Parkinson, "Imagine The Pandemic Without Computer Science," https://www.youtube.com/watch?v= MDrdz7rRDN0, February 2021.

[28] Y. Dwivedi, L. Hughes, E. Ismagilova, G. Aarts, C. Coombs, T. Crick, Y. Duan, R. Dwivedi, J. Edwards, A. Eirug, V. Galanos, P. V. Ilavarasan, M. Janssen, P. Jones, A. Kumar Kar, H. Kizgin, B. Kronemann, B. Lal, B. Lucini, R. Medaglia, K. Le Meunier-FitzHugh, L. Le Meunier-FitzHugh, S. Misra, E. Mogaji, S. Sharma, J. Bahadur Singh, V. Raghavan, R. Raman, N. Rana, S. Samothrakis, J. Spencer, K. Tamilmani, A. Tubadji, P. Walton, and M. Williams, "Artificial Intelligence (AI): Multidisciplinary Perspectives on Emerging Challenges, Opportunities, and Agenda for Research, Practice and Policy," International Journal of Information Management, vol. 53, no. 101994, 2021.

[29] D. Ting, L. Carin, V. Dzau, and T. Y. Wong, "Digital technology and COVID-19," Nature Medicine, vol. 26, pp. 459-461, 2020.

[30] V. G. Cerf, "Implications of the COVID-19 pandemic," Communications of the ACM, vol. 63, no. 6, 2020.

[31] S. Chun, A. Li, A. Li, A. Toliyat, and J. Geller, "Tracking Citizen's Concerns during COVID-19 Pandemic," in Proc. 21st Annual International Conference on Digital Government Research. ACM, 2020.

[32] BBC News, "Coronavirus: What went wrong with the UK's contact tracing app?" https://www.bbc.co.uk/news/technology-53114251, June 2020.

[33] A. Zhigljavsky, R. Whitaker, I. Fesenko, K. Kremnizer, J. Noonan, P. Harper, J. Gillard, T. Woolley, D. Gartner, J. Grimsley, E. de Arruda, V. Fedorovk, and T. Crick, "Generic probabilistic modelling and non-homogeneity issues for the UK epidemic of COVID-19," https://arxiv.org/abs/2004.01991, 2020.

[34] CRA, "Reports on Surveys of Computer Science Faculty and Academic Units/Chairs: COVID-19 Impact," https://cra.org/reports-on-surveys-ofcomputer-science-faculty-and-academic-units-chairs-covid-19-impact/, 2020.

[35] T. Crick, C. Knight, R. Watermeyer, and J. Goodall, "An Overview of the Impact of COVID-19 and "Emergency Remote Teaching" on International CS Education Practitioners," in Proc. 52nd ACM Technical Symposium on Computer Science Education (SIGCSE'21). ACM, 2021. 
[36] OECD, "Science in the face of the COVID-19 crisis," https:// oecdsciencesurveys.github.io/2020flashsciencecovid/, July 2020.

[37] Microsoft Research, "Impact of COVID-19 on the Computer Science Research Community," https://www.microsoft.com/en-us/research/ project/academic/articles/impact-of-covid-19-on-computer-scienceresearch-community/, March 2020.

[38] R. Watermeyer, T. Crick, C. Knight, and J. Goodall, "COVID-19 and digital disruption in UK universities: afflictions and affordances of emergency online migration," Higher Education, vol. 81, 2021.

[39] T. Crick, C. Knight, R. Watermeyer, and J. Goodall, "The Impact of COVID-19 and "Emergency Remote Teaching" on the UK Computer Science Education Community," in Proc. UK and Ireland Computing Education Research Conference (UKICER'20). ACM, 2020.

[40] N. C. C. Brown, M. Kölling, T. Crick, S. Peyton Jones, S. Humphreys, and S. Sentance, "Bringing Computer Science Back Into Schools: Lessons from the UK," in Proc. 44th ACM Technical Symposium on Computer Science Education (SIGCSE'13), 2013, pp. 269-274.

[41] N. C. C. Brown, S. Sentance, T. Crick, and S. Humphreys, "Restart: The Resurgence of Computer Science in UK Schools," ACM Transactions on Computer Science Education, vol. 14, no. 2, pp. 1-22, 2014.

[42] J. H. Davenport, T. Crick, and R. Hourizi, "The Institute of Coding: A University-Industry Collaboration to Address the UK's Digital Skills Crisis," in Proc. IEEE Global Engineering Education Conference (EDUCON2020), 2020, pp. 1400-1408.

[43] European Parliament, "COVID-19: the EU plan for the economic recovery," https://www.europarl.europa.eu/news/en/headlines/economy/ 20200513STO79012/covid-19-the-eu-plan-for-the-economic-recovery, July 2020.

[44] McKinsey \& Company, "Lessons from the past on how to revive the US economy after COVID-19," https://www.mckinsey.com/industries/ public-and-social-sector/our-insights/lessons-from-the-past-on-how-torevive-the-us-economy-after-covid-19, June 2020.

[45] ACM, "Curricula Recommendations," https://www.acm.org/education/ curricula-recommendations, 2017.

[46] V. Braun and V. Clarke, "Using thematic analysis in psychology," Qualitative Research in Psychology, vol. 3, no. 2, pp. 77-101, 2006.

[47] J. Reich, C. Buttimer, D. Coleman, R. Colwell, F. Faruqi, and L. Larke, "What's Lost, What's Left, What's Next: Lessons Learned from the Lived Experiences of Teachers during the 2020 Novel Coronavirus Pandemic," July 2020, MIT Teaching Systems Lab.

[48] National Academies of Sciences, Engineering, and Medicine, Teaching K-12 Science and Engineering During a Crisis, 2020.

[49] E. Marchant, C. Todd, M. James, T. Crick, R. Dwyer, and S. Brophy, "Primary school staff reflections on school closures due to COVID19 and recommendations for the future: a national qualitative survey," https://doi.org/10.1101/2020.11.06.20227108, 2020.

[50] Department for Education, UK Government, "Awarding qualifications in summer 2021," https://www.gov.uk/government/publications/awardingqualifications-in-summer-2021, February 2021.

[51] T. Crick, T. Prickett, J. H. Davenport, and A. Irons, "Assessing the Value of Professional Body Accreditation of Computer Science Degree Programmes: A UK Case Study," in Proc. 25th Annual Conference on Innovation and Technology in Computer Science Education (ITiCSE'20). ACM, 2020

[52] A. Irons, T. Crick, J. H. Davenport, P. Hanna, and T. Prickett, "Increasing the Value of Professional Body Computer Science Degree Accreditation," in Proc. 52nd ACM Technical Symposium on Computer Science Education (SIGCSE'21). ACM, 2021

[53] R. Ward, O. Phillips, D. Bowers, T. Crick, J. H. Davenport, P. Hanna, A. Hayes, A. Irons, and T. Prickett, "Towards a 21 st century personalised learning skills taxonomy," in Proc. IEEE Global Engineering Education Conference (EDUCON'21). IEEE, 2021.

[54] T. Crick, "COVID-19 and Digital Education: A Catalyst for Change?" ITNOW, vol. 63, no. 1, pp. 16-17, 2021.

[55] A. Harris, M. Jones, and T. Crick, "Curriculum leadership: a critical contributor to school and system improvement," School Leadership \& Management, vol. 40, no. 1, pp. 1-4, 2020.

[56] G. Watts, "COVID-19 and the digital divide in the UK," The Lancet Digital Health, vol. 2, no. 8, pp. E395-E396, 2020.

[57] E. Beaunoyer, S. Dupéré, and M. J. Guitton, "COVID-19 and digital inequalities: Reciprocal impacts and mitigation strategies," Computers in Human Behavior, vol. 111, no. 106424, 2020.

[58] B. Williamson, R. Eynon, and J. Potter, "Pandemic politics, pedagogies and practices: digital technologies and distance education during the coronavirus emergency," Learning, Media and Technology, vol. 45, no. 2, pp. 107-114, 2020.

[59] F. Moller and T. Crick, "A University-Based Model for Supporting Computer Science Curriculum Reform," Journal of Computers in Education, vol. 5, no. 4, pp. 415-434, 2018.

[60] T. Bell, "Establishing a nationwide CS curriculum in New Zealand high schools," Communications of the ACM, vol. 57, no. 2, pp. 28-30, 2014.

[61] J. Gal-Ezer and C. Stephenson, "A Tale of Two Countries: Successes and Challenges in K-12 Computer Science Education in Israel and the United States," ACM Transactions on Computer Science Education, vol. 14(2), no. 8, 2014.

[62] R. Raman, S. Venkatasubramanian, K. Achuthan, and P. Nedungadi, "Computer Science (CS) Education in Indian Schools: Situation Analysis using Darmstadt Model," ACM Transactions on Computer Science Education, vol. 15(2), no. 7, 2015.

[63] J. H. Davenport, A. Hayes, R. Hourizi, and T. Crick, "Innovative Pedagogical Practices in the Craft of Computing," in Proc. 4th International Conference on Learning and Teaching in Computing and Engineering (LaTiCE 2016), 2016.

[64] E. Murphy, T. Crick, and J. H. Davenport, "An Analysis of Introductory Programming Courses at UK Universities," The Art, Science, and Engineering of Programming, vol. 1(2), no. 18, 2017.

[65] Simon, R. Mason, T. Crick, J. H. Davenport, and E. Murphy, "Language Choice in Introductory Programming Courses at Australasian and UK Universities," in Proc. 49th ACM Technical Symposium on Computer Science Education (SIGCSE'18). ACM, 2018, pp. 852-857.

[66] J. H. Davenport and T. Crick, "Cybersecurity Education and Formal Methods," in Formal Methods - Fun for Everybody, ser. Communications in Computer and Information Science. Springer, 2021, vol. 1301.

[67] T. Crick, J. H. Davenport, P. Hanna, A. Irons, and T. Prickett, "Overcoming the Challenges of Teaching Cybersecurity in UK Computer Science Degree Programmes," in Proc. 50th Annual Frontiers in Education Conference (FIE'20), 2020.

[68] T. Prickett, M. Harvey, J. Walters, L. Yang, and T. Crick, "Resilience and Effective Learning in First-Year Undergraduate Computer Science," in Proc. 25th Annual Conference on Innovation and Technology in Computer Science Education (ITiCSE'20), 2020.

[69] T. Crick, J. H. Davenport, A. Irons, and T. Prickett, "A UK Case Study on Cybersecurity Education and Accreditation," in Proc. 49th Annual Frontiers in Education Conference (FIE'19), 2019, pp. 1-9.

[70] T. Crick, J. H. Davenport, A. Irons, S. Pearce, and T. Prickett, "Maintaining the Focus on Cybersecurity in UK Higher Education," ITNOW, vol. 61, no. 4, pp. 46-47, 2019.

[71] T. Crick, J. H. Davenport, P. Hanna, A. Irons, and T. Prickett, "Computer Science Degree Accreditation in the UK: A Post-Shadbolt Review Update," in Proc. Computing Education Practice (CEP'21), 2020.

[72] T. Crick, J. H. Davenport, P. Hanna, A. Irons, S. Pearce, and T. Prickett, "Repositioning BCS Degree Accreditation," ITNOW, vol. 62, no. 1, pp. $50-51,2020$.

[73] A. Hayes, J. H. Davenport, A. Irons, T. Prickett, and T. Crick, "Integrating New Research Faculty into the UK Computer Science Education Community," in Proc. UK and Ireland Computing Education Research Conference (UKICER'20). ACM, 2020.

[74] T. Crick, J. H. Davenport, A. Hayes, A. Irons, and T. Prickett, "Supporting Early-Career Academics in the UK Computer Science Community," in Proceedings of Computing Education Practice (CEP'21). ACM, 2021.

[75] T. Tryfonas and T. Crick, "Public Policy and Skills for Smart Cities: The UK Outlook," in Proc. 11th International Conference on PErvasive Technologies Related to Assistive Environments (PETRA'18). ACM, 2018, pp. 116-117.

[76] J. H. Davenport, T. Crick, A. Hayes, and R. Hourizi, "The Institute of Coding: Addressing the UK Digital Skills Crisis," in Proc. Computing Education Practice (CEP'19). ACM, 2019.

[77] Financial Times, "COVID-19 is changing education for the better," https://www.ft.com/content/51496fde-98e7-11ea-871b-edeb99a20c6e, May 2020.

[78] - "Crisis requires co-ordinated digital response," https://www.ft.com/content/b645d2f8-89f9-11ea-a109-483c62d17528, April 2020.

[79] Y. Zhao, "COVID-19 as a catalyst for educational change," $P R O$ SPECTS, vol. 49, pp. 29-33, 2020.

[80] E. Strickland and G. Zorpette, "Prepping for the Next Big One," IEEE Spectrum, October 2020. 